\title{
GAMBARAN LAMA TIDUR TERHADAP PRESTASI BELAJAR SISWA
}

\author{
${ }^{1}$ Panangian P. Marpaung \\ ${ }^{2}$ Siantan Supit \\ ${ }^{2}$ Joice Nancy
}

\author{
${ }^{1}$ Kandidat Skripsi Kedokteran Universitas Sam Ratulangi Manado \\ ${ }^{2}$ Bagian Fisiologi Fakultas Kedokteran Universitas Sam Ratulangi Manado \\ Email: Paulzomega441@gmail.com
}

\begin{abstract}
Inadequate sleep leads to concentrating distraction, fatigue, mood and productivity disorder, etc. Therefore, these matters could contribute influence in teenagers, especially to their academic performance. Adequate sleeping length is needed by the body to maximize the student's ability in effort of achieving a good academic performance. This descriptive study using cross sectional design. The samples were the students of SMA Binsus Manado. Samples consist of 116 students including male and female ranging in age from 15 to 18 years old. This study using a sleeping length questionnaire for figure out the distribution of the respondent's sleeping length and to evaluate the student's academic performance by using their mid-term exam results. The results of this study are presented in respondent distribution table. The highest number of $49,1 \%$ occupies a high academic performance with adequate sleep. The rest distributes as $22,4 \%$ in medium academic performance with adequate sleep, $6,0 \%$ in low academic performance with adequate sleep. $14,7 \%$ in high academic performance but with inadequate sleep, $6,9 \%$ in medium academic performance with inadequate sleep, and $0,9 \%$ with low academic performance and inadequate sleep. Generally, the students with adequate sleep result in high academic performance.
\end{abstract}

Key words: description, sleeping length, studying performance, student.

\begin{abstract}
Abstrak: Kurang tidur cenderung menyebabkan gangguan konsentrasi, kelelahan, gangguan mood, produktivitas, dan lain-lain sehingga dapat mempengaruhi remaja terutama terhadap prestasi belajar. Lama tidur yang cukup dibutuhkan tubuh untuk memaksimalkan kemampuan siswa dalam usaha mencapai prestasi belajar yang baik. Penelitian ini merupakan penelitian deskriptif dengan desain penelitian cross sectional. Sampel merupakan siswa SMA Binsus Manado. Sampel berjumlah 116 orang laki-laki maupun perempuan dengan rentang usia 1518 tahun. Untuk mengetahui distribusi lama tidur responden, digunakan kuesioner lama tidur sedangkan untuk menilai prestasi belajar digunakan nilai ujian mid semester. Hasil yang diperoleh disajikan dalam bentuk tabel distribusi responden dengan jumlah terbanyak sebesar 49,1\% responden dengan prestasi tinggi dan cukup tidur Sisanya terdistribusi di 22,4\% responden berprestasi sedang dan cukup tidur, 6,0\% responden berprestasi rendah namun cukup tidur. Ada juga 14,7\% responden berprestasi tinggi namun tidak cukup tidur, 6,9\% responden berprestasi sedang namun tidak cukup tidur, serta 0,9\% responden berprestasi rendah dan kurang tidur. Pada umumnya, siswa yang cukup tidur memiliki prestasi belajar yang tinggi.
\end{abstract}

Kata Kunci: gambaran, lama tidur, prestasi belajar, siswa. 
Tidur adalah salah satu aktivitas terpenting manusia. Bila aktivitas ini dijalani seseorang dengan baik, maka efeknya akan mengenai dimensi kehidupan seseorang diwaktu terjaga. Tidur memiliki pengaruh terhadap kewaspadaan, energi, konsentrasi dan seterusnya. ${ }^{1}$

Dewasa ini, sebagian besar umat manusia mengalami kualitas tidur yang kurang optimal. Misalnya sejak adanya televisi, orang cenderung tidur lebih larut. Di Indonesia, sejak adanya berbagai televisi swasta di awal tahun 1900-an hingga pesatnya perkembangan teknologi siaran televisi saat ini, ada kecenderungan masyarakat mengkonsumsi acara televisi hingga larut malam. Akibat yang muncul adalah seseorang tidak dapat berkonsentrasi secara penuh. ${ }^{1}$

Waktu untuk tidur adalah malam hari, sedangkan waktu untuk tidak tidur adalah siang hari. Pada waktu malam hari, manusia cenderung tidak memiliki aktivitas berlebih dan juga keadaan yang sunyi senyap menjadi alasan yang membuat malam menjadi waktu yang tepat untuk beristirahat. $^{2}$

Efek terburuk dari tidur yang buruk bukanlah bagaimana kita merasakannya di malam hari akan tetapi bagaimana hal itu mempengaruhi kita di siang hari, baik secara fisik maupun emosional. Menurut hasil survei sebuah studi tidur di Inggris didapati bahwa orang yang kurang tidur cenderung 3 kali lebih besar menderita gangguan konsentrasi, 2 kali menderita kelelahan, gangguan mood, produktivitas, dan lain-lain. ${ }^{4}$

Batas maksimal tanpa tidur yang tercatat sejauh ini adalah 264 jam atau sekitar 11 hari. Jika tanpa makan, manusia mampu bertahan sekitar 40 hari. Sementara tanpa minum, sekitar 3 hari. Apabila dibuat berurutan, berarti aktivitas paling vital dalam hidup manusia adalah udara (bernafas), cairan (minum), tidur dan makan. Udara menduduki peringkat pertama karena beberapa menit saja tanpa udara manusia tidak dapat bertahan hidup. ${ }^{2}$

Setiap manusia memiliki kebiasaan tidur yang berbeda-beda. Salah satunya tergantung dari aktiitas yang dilakukan. Mulai dari usia balita sampai lansia memiliki waktu tidur yang berbeda. Salah satu tahap paling unik adalah waktu tidur di usia Remaja. Masa Remaja di bagi menjadi 2, yaitu masa dewasa muda (usia16-30 tahun) dan dewasa tua (usia 31-60). ${ }^{2}$

Keunikan justru terjadi pada masa usia dewasa muda dimana terjadi pergeseran irama sirkadian sehingga jam tidur pun bergeser akibat dari perubahan hormonal yang terjadi pada akhir masa pubertas. Secara umum, kebutuhan tidur remaja akan meningkat menjadi 8,5-9,25 jam setiap hari akan tetapi waktu tidurnya berubah. Uniknya, saat orang lain mulai mengantuk pada pukul 21.00 atau 22.00, ia justru bersemangat untuk berkarya, baik itu belajar maupun menyelesaikan pekerjaannya. ${ }^{2}$

Sementara di pagi hari, remaja sudah harus bangun lebih awal untuk mempersiapkan diri ke sekolah, kuliah, maupun bekerja. Pada umumnya, remaja mengalami kekurangan tidur sehingga tidak mengherankan jika banyak fenomena pelajar atau mahasiswa yang tertidur saat jam pelajaran dimulai. $^{2}$

Sampai saat ini di Indonesia masih jarang dilakukan penelitian yang berkaitan dengan tidur dan permasalahannya, terutama di kalangan siswa. Ironisnya, berdasarkan penelitian-penelitian di Amerika Serikat dan Eropa, siswa SMA dan Mahasiswa merupakan kelompok yang paling rentan menderita kurang tidur kronis. Akibatnya mereka mempunyai risiko yang lebih tinggi dalam mengalami dampak negatif yang ditimbulkan. ${ }^{5}$

\section{METODE PENELITIAN}

Jenis penelitian yang digunakan adalah studi deskriptif yaitu penelitian yang diarahkan untuk mengetahui gambaran antara variabel independen yaitu lama tidur terhadap variabel dependen yaitu prestasi belajar.

Pendekatan yang digunakan adalah pendekatan cross sectional survey yaitu dimana peneliti melakukan pengumpulan data baik dari variabel independen maupun 
variabel dependen dilakukan dalam satu kali pengambilan. Lokasi penelitian ini dilaksanakan di SMA Binsus Manado, Sulawesi Utara. Waktu penelitian ini dilaksanakan pada bulan November sampai bulan Desember 2012. Populasi dari penelitian ini ialah seluruh Siswa SMA Binsus Manado. Sampel dari penelitian ini ialah siswa kelas 3 SMA Binsus yang memenuhi kriteria Inklusi. Sampel diambil menggunakan rumus Simpel Random Sampling yaitu: ${ }^{6}$

$\mathrm{n}=\frac{\mathrm{Z}_{\alpha} \mathrm{PQ}}{\mathrm{D}^{2}}$ Dengan, $\mathrm{P}=$ Proporsi penyakit atau keadaan yang akan dicari (dari pustaka) $\mathrm{D}=$ Tingkat ketepatan absolut yang dikehendaki (ditetapkan) $\alpha=$ Tingkat kemaknaan (ditetapkan). Karena PxQ mempunyai nilai paling tinggi bila $\mathrm{P}=0,50$, bila proporsi sebelumnya tidak diketahui, maka pada subyek yang dipilih secara simple random sampling dipergunakan : $\mathrm{P}=$ 0,$50 ; Z_{\alpha}=1,96 ; D=0,10$ Maka estimasi besar sample pada penelitian ini :

$$
\mathrm{n}=\frac{1,96^{2} \times 0,50 \times(1-0,50)}{0,10^{2}}=97
$$

jadi, sampel minimal yang harus terpenuhi ialah 97 responden.

Kriteria Inklusi penelitian ini yaitu sehat jasmani dan rohani pada saat wawancara serta umur antara 16-19 tahun. Definisi operasional tidur ialah aktivitas susunan saraf pusat yang berperan sebagai lonceng Biologic. ${ }^{3}$ Lama Tidur untuk Usia 16-18 tahun adalah 8,5 jam/hari. ${ }^{2}$ Prestasi belajar menurut Winkel adalah suatu bukti keberhasilan belajar atau kemampuan seseorang siswa dalam melakukan kegiatan belajarnya sesuai dengan bobot yang dicapainya. ${ }^{7}$ Pengukuran prestasi belajar menggunakan nilai raport.

\section{HASIL PENELITIAN}

Total sampel pada siswa kelas 3 SMA Binsus Manado yang ada sebanyak 126 siswa. Akan tetapi, yang memenuhi kriteria inklusi berjumlah 116. Jadi, sampel yang akan digunakan dalam penelitian ini berjumlah 116 untuk menghindari bias sampel.

Tabel 1. Distribusi responden cukup tidur berdasarkan umur

\begin{tabular}{ccccccc}
\hline \multirow{2}{*}{ No } & \multirow{2}{*}{ Umur } & \multicolumn{2}{c}{ Cukup tidur } & \multicolumn{2}{c}{ Kurang tidur } \\
\cline { 3 - 6 } & & $\mathbf{n}$ & $\mathbf{\%}$ & $\mathbf{n}$ & $\mathbf{\%}$ \\
\hline 1. & 15 & 9 & 7,7 & 0 & 0,0 \\
2. & 16 & 37 & 31,9 & 13 & 11,2 \\
3. & 17 & 43 & 37,1 & 13 & 11,2 \\
4. & 18 & 1 & 0,9 & 0 & 0,0 \\
\hline Jumlah & & 90 & 77,6 & 26 & 22,4 \\
\hline
\end{tabular}

Tabel 2. Distribusi responden cukup tidur berdasarkan jenis kelamin

\begin{tabular}{cccccc}
\hline \multirow{2}{*}{ No } & \multirow{2}{*}{ Jenis Kelamin } & \multicolumn{2}{c}{ Cukup tidur } & \multicolumn{2}{c}{ Kurang tidur } \\
\cline { 3 - 6 } & & $\mathbf{n}$ & $\mathbf{\%}$ & $\mathbf{n}$ & $\mathbf{\%}$ \\
\hline 1. & Laki - laki & 34 & 29,3 & 9 & 7,7 \\
2. & Perempuan & 56 & 48,3 & 17 & 14,7 \\
\hline Jumlah & & 90 & 77,6 & 26 & 22,4 \\
\hline
\end{tabular}

Berdasarkan distribusi pada tabel 1, dapat diketahui bahwa kelompok responden terbesar berada pada umur 17 tahun sebanyak 56 siswa (48,2 \%), kemudian 16 tahun sebanyak 50 siswa
(43,1 \%), 15 tahun sebanyak 9 siswa $(7,8$ $\%)$, dan yang terkecil di umur 18 tahun sebanyak 1 siswa (0,9\%).

Berdasarkan distribusi pada tabel 2, dapat diketahui bahwa kelompok 
responden terbesar berada pada Jenis Kelamin Perempuan sebanyak 73 siswa (62,9\%) sedangkan pada Laki-laki sebanyak 43 siswa (37,1\%).

Berdasarkan distribusi pada tabel 3, dapat diketahui bahwa kelompok responden terbesar sebanyak 49 siswa $(42,2 \%)$ tidur malam selama 6-7 jam, 7-8 jam memiliki responden sebanyak 40 siswa (34,5\%), 22 responden (19\%) tidur selama 5-6 jam, sedangkan responden paling sedikit berjumlah 5 siswa (4,3\%) tidur malam selama $<5$ jam.

Berdasarkan distribusi responden pada tabel 4, dapat diketahui bahwa responden terbesar sebanyak 50 siswa $(43,1 \%)$ membutuhkan waktu untuk terlelap dalam tidur dimalam hari selama 16-30 menit, disusul dengan 48 siswa $(41,4 \%)$ selama $<$ 15 menit, 11 siswa $(9,5 \%)$ selama $31-60$ menit, dan 7 siswa (6,0\%) membutuhkan waktu untuk terlelap dalam tidur selama $>$ 60 menit.

Berdasarkan distribusi responden pada tabel 5, dapat diketahui bahwa responden terbesar sebanyak 85 siswa (73,3\%) kadang-kadang mengantuk pada saat mengikuti kegiatan belajar mengajar di kelas, 22 siswa (19,0\%) sering mengantuk pada saat mengikuti kegiatan belajar mengajar di kelas, 5 siswa (4,3\%) selalu mengantuk pada saat mengikuti kegiatan belajar mengajar di kelas, dan yang terakhir sebanyak 4 siswa $(3,4 \%)$ tidak pernah mengantuk pada saat mengikuti kegiatan belajar mengajar di kelas.

Tabel 3. Distribusi responden berdasarkan lama waktu yang dibutuhkan untuk tidur di malam hari

\begin{tabular}{cccc}
\hline No & $\begin{array}{c}\text { Lama waktu yang dibutuhkan untuk } \\
\text { tidur dimalam hari. }\end{array}$ & $\mathbf{n}$ & Presentase (\%) \\
\hline 1. & $7-8$ jam & 40 & 34,5 \\
2. & $6-7$ jam & 49 & 42,2 \\
3. & $5-6$ jam & 22 & 19,0 \\
4. & $<5$ jam & 5 & 4,3 \\
\hline Jumlah & & 116 & 100 \\
\hline
\end{tabular}

Tabel 4. Distribusi responden berdasarkan waktu yang dibutuhkan untuk terlelap dalam tidur di malam hari

\begin{tabular}{cccc}
\hline No & $\begin{array}{c}\text { Waktu yang dibutuhkan untuk } \\
\text { terlelap dalam tidur dimalam hari. }\end{array}$ & n & Presentase (\%) \\
\hline 1. & $<15$ menit & 48 & 41,4 \\
2. & $16-30$ menit & 50 & 43,1 \\
3. & $31-60$ menit & 11 & 9,5 \\
4. & $>60$ menit & 7 & 6,0 \\
\hline Jumlah & & 116 & 100 \\
\hline
\end{tabular}

Tabel 5. Distribusi responden berdasarkan frekuensi mengantuk pada saat mengikuti kegiatan belajar mengajar di kelas

\begin{tabular}{cccc}
\hline No & $\begin{array}{c}\text { Frekuensi mengantuk pada saat mengikuti } \\
\text { kegiatan belajar mengajar di kelas. }\end{array}$ & n & Presentase (\%) \\
\hline 1. & Selalu & 5 & 4,3 \\
2. & Sering & 22 & 19,0 \\
3. & Kadang-kadang & 85 & 73,3 \\
4. & Tidak pernah & 4 & 3,4 \\
\hline Jumlah & & 116 & 100 \\
\hline
\end{tabular}


Tabel 6. Distribusi responden berdasarkan mata pelajaran yang paling disukai

\begin{tabular}{cccc}
\hline No & Mata pelajaran yang paling disukai & n & Presentase (\%) \\
\hline 1. & Biologi & 30 & 25,9 \\
2. & Matematika & 29 & 25,0 \\
3. & Kimia & 10 & 8,6 \\
4. & Fisika & 3 & 2,6 \\
5. & Bahasa Indonesia & 2 & 1,7 \\
6. & Bahasa inggris & 18 & 15,5 \\
7 & PKN & 1 & 0,9 \\
8. & Sejarah & 0 & 0,0 \\
9. & Seni & 8 & 6,9 \\
10. & Penjas & 0 & 0,0 \\
11. & TIK & 8 & 6,9 \\
12. & Agama & 2 & 1,7 \\
13. & Mulok & 2 & 1,7 \\
14. & Bahasa asing & 3 & 2,6 \\
\hline Jumlah & & 116 & 100 \\
\hline
\end{tabular}

Tabel 7. Distribusi responden berdasarkan prestasi belajar

\begin{tabular}{cccc}
\hline No & Prestasi belajar & n & Presentase (\%) \\
\hline 1. & Tinggi & 74 & 63,8 \\
2. & Sedang & 34 & 29,3 \\
3. & Rendah & 8 & 6,9 \\
\hline Jumlah & & 116 & 100 \\
\hline
\end{tabular}

Tabel 8. Distribusi responden cukup tidur berdasarkan prestasi belajar

\begin{tabular}{cccccl}
\hline \multirow{2}{*}{ No } & \multirow{2}{*}{ Prestasi } & \multicolumn{2}{c}{ Cukup tidur } & \multicolumn{2}{c}{ Kurang tidur } \\
\cline { 3 - 6 } & & $\mathbf{n}$ & $\mathbf{\%}$ & $\mathbf{n}$ & $\mathbf{\%}$ \\
\hline 1. & Tinggi & 57 & 49,1 & 17 & 14,7 \\
2. & Sedang & 26 & 22,4 & 8 & 6,9 \\
3. & Rendah & 7 & 6,0 & 1 & 0,9 \\
\hline Jumlah & & 90 & 77,5 & 26 & 22,5 \\
\hline
\end{tabular}

Berdasarkan distribusi responden pada tabel 6, dapat diketahui bahwa responden terbesar sebanyak 32 siswa $(27,6 \%)$ menyukai biologi, 28 siswa $(24,1 \%)$ menyukai matematika, 10 siswa $(8,6 \%)$ menyukai bahasa Indonesia, 9 siswa $(7,8 \%)$ menyukai bahasa inggris, 8 siswa $(6,9 \%)$ menyukai TIK, 8 siswa (6,9\%) menyukai kimia, 6 siswa $(5,1 \%)$ menyukai seni, 5 siswa (4,3\%) menyukai sejarah, 4 siswa (3,5\%) menyukai agama, 3 siswa $(2,6 \%)$ menyukai fisika, 2 siswa (1,7\%) menyukai bahasa asing, 1 siswa $(0,9)$ menyukai PKN.

Berdasarkan distribusi responden pada tabel 7, dapat diketahui bahwa responden terbesar sebanyak 74 siswa $(63,8 \%)$ memiliki prestasi tinggi, 34 siswa $(29,3 \%)$ memiliki prestasi sedang, serta 8 siswa (6,9\%) memiliki nilai rendah.

Berdasarkan distribusi responden pada tabel 8, dapat diketahui bahwa responden terbesar sebanyak 57 siswa (49,1\%) berada pada posisi prestasi tinggi serta cukup tidur. Sisanya terdistribusi pada 26 siswa $(22,4 \%)$ berprestasi sedang serta cukup tidur, 7 siswa $(6,0 \%)$ prestasi rendah namun cukup tidur. Ada juga 17 siswa (14,7\%) berprestasi tinggi namun tidak cukup tidur, 8 siswa (6,9\%) berprestasi sedang namun tidak cukup tidur, serta 1 orang dengan 
prestasi rendah dan kurang tidur.

\section{DISKUSI}

Responden terbanyak berasal dari umur 17 tahun yaitu 56 siswa (48,2\%), dan terbesar kedua berasal dari kelompok umur 16 tahun. Bila dibandingkan dengan hasil penelitian oleh Nur Aini, yang mengkaji hubungan antara pola tidur dengan prestasi belajar pada siswa SMA Dharma Pancasila Medan (2011) dengan jumlah responden 85 siswa hasil yang didapatkan sama, yaitu responden terbesar berada pada umur 16-17 tahun. ${ }^{8}$

Demikian pula dengan distribusi responden berdasarkan jenis kelamin. Didapatkan 73 siswa (62,9\%) perempuan lebih banyak dari pria 43 siswa $(37,1 \%)$ hal ini sejalan dengan penelitian Dewi S yang meneliti tentang prevalensi kurang tidur kronis pada mahasiswa. Dalam penelitian tersebut disebutkan bahwa tidak ada hubungan yang signifikan antara jenis kelamin dengan prevalensi kurang tidur kronis. $^{8}$

Distribusi responden berdasarkan waktu yang dibutuhkan untuk tidur dimalam hari terbanyak berada pada pilihan 6-7 jam yaitu 49 siswa (42,2\%) hanya selisih 9 responden dengan pilihan 7-8 jam yaitu 40 siswa (34,5\%), sedangkan sisanya terdistribusi pada pilihan 5-6 jam yaitu 22 siswa $(19,0 \%)$ dan $<5$ jam yaitu 5 siswa (4,3\%). Hal ini sesuai dengan pendapat responden pada tabel 3 bahwa siswa di tengah kesibukan persiapan UAN dan aktivitas lainnya, tubuh mulai terbiasa beradaptasi dengan kebutuhan tidur dimana aktifnya otak remaja berada pada pukul 9 malam. Sementara remaja harus bangun pagi untuk berangakat ke sekolah. Hal itulah yang menyebabkan tubuh perlahan beradaptasi dengan berkurangnya waktu tidur seiring berjalannya waktu. ${ }^{2}$

Distribusi responden berdasarkan waktu yang dibutuhkan untuk terlelap dalam tidur, kelompok terbanyak memilih 16-30 menit yaitu, 50 siswa (43,1\%) selisih 2 responden dengan pilihan $<15$ menit yaitu 48 siswa $(41,4 \%)$. Sisanya ter- distribusi pada pilihan 31-60 menit 11 siswa $(9,5 \%)$ dan $>60$ menit 7 siswa $(6,0 \%)$. Hal ini terjadi dikarenakan sebagian besar siswa memiliki stressor dan kecemasan yang lebih besar akibat padatnya jadwal kegiatan di sekolah menjelang semester akhir serta banyaknya tugas yang harus dihadapi. ${ }^{5}$

Mengantuk saat mengikuti kegiatan belajar mengajar telah menjadi hal yang umum. Sebanyak 85 siswa (73,3\%) kadang-kadang mengantuk saat mengikuti kegiatan belajar mengajar sedangkan sedikit yang sering mengantuk yaitu 22 siswa (19,0\%), 5 siswa (4,3\%) selalu mengantuk, dan 4 siswa (3,4\%) tidak pernah mengantuk pada saat mengikuti kegiatan belajar mengajar di kelas. Artinya, masih banyak responden yang kadang-kadang mengantuk dikelas. Faktor lingkungan dan sosioekonomi juga berperan penting dalam hal ini. Aktifitas yang dilakukan malam harinya berpengaruh besar selain daripada pola tidur yang salah. ${ }^{8}$

Mengenai prestasi belajar, kuesioner yang disajikan lebih mengarah pada proses analisa dari konsentrasi belajar siswa karena konsentrasi merupakan inti paling vital dalam menentukan prestasi belajar seorang siswa.

Distribusi responden yang memilih sendiri mata pelajaran yang disukai, memiliki kecenderungan memilih mata pelajaran yang dirasa mampu oleh siswa. Dari hasil olah data, didapati bahwa mata pelajaran Biologi menempati urutan pertama dengan 30 siswa $(25,9 \%)$ disusul Matematika dengan 29 siswa (25,0\%) serta Bahasa Inggris dengan 18 siswa (15,5\%). Hal ini mengindikasikan bahwa peminatnya beragam. Ketika disesuaikan dengan nilai raport, hasilnya sangat baik. Hal itu sejalan dengan pendapat responden mengenai apakah responden berprestasi dalam bidang yang disukainya. 90 siswa (77,6\%) menjawab bahwa mereka berprestasi dalam bidang yang mereka sukai. Meskipun ada juga 26 siswa $(22,4 \%)$ menjawab tidak. Artinya sebagian besar responden memiliki kemampuan yang baik dalam bidang yang disukainya meskipun 
banyak faktor yang berperan penting. ${ }^{8}$

Prestasi belajar secara umum yang dimiliki SMA Binsus cukup baik. Hal ini ditunjukkan dalam tabel distribusi responden berdasarkan prestasi belajar sebanyak 74 siswa $(63,8 \%)$ memiliki prestasi baik dan tabel distribusi responden cukup tidur berdasarkan prestasi belajar dimana didapatkan bahwa 57 siswa $(49,1 \%)$ memiliki prestasi yang tinggi serta cukup tidur. Hal ini mengindikasikan bahwa sebagian besar responden sudah memiliki kesadaran dan adaptasi dalam mengatur pola tidur serta mampu memaksimalkam fungsi tubuh dengan memanfaatkan waktu istirahat yang cukup. Meskipun didapatkan responden yang belum mampu memaksimalkan waktu tidur dengan baik, akan tetapi secara kese-luruhan, sudah cukup baik. ${ }^{8}$

\section{SIMPULAN DAN SARAN}

Kesimpulan yang dapat ditarik dari penelitian ini, yaitu pada umumnya, siswa yang cukup tidur memiliki prestasi belajar yang tinggi yaitu sebesar 49,1\%. Prevalensi lama tidur pada siswa kelas 3 di SMA Binsus Manado berkisar antara 6-7 jam artinya, prevalensi lama tidur siswa baik. Tingkat prestasi belajar siswa kelas 3 di SMA Binsus Manado dikategorikan memuaskan.

Penelitian ini bisa dijadikan masukan dan informasi kepada pihak sekolah supaya dapat direncanakan upaya dalam memperbaiki pola tidur siswa dan sekaligus meningkatkan prestasi akademik siswa. Pihak administrasi sekolah, disarankan supaya dilakukan konseling siswa untuk menilai serta mengkaji bagaimana timbulnya masalah-masalah dalam pola tidur pada siswa agar masalah tersebut dapat teratasi dan siswa dapat lebih menumpukan perhatian dalam pembelajaran. Pihak orang tua/wali siswa agar lebih mengontrol kegiatan siswa serta dapat mengawasi jam tidur siswa.

\section{UCAPAN TERIMA KASIH}

Ucapan terima kasih disampaikan pada dr. J. J. V. Rampengan, AIFM, AIFO, dr. S. R. Marunduh, MMed, AIFM, AIFO serta kepada semua pihak yang baik secara langsung maupun tidak langsung telah menumbuhkan ide atau gagasan dalam pemikiran penulis sehingga dapat menyelesaikan artikel ini.

\section{DAFTAR PUSTAKA}

1. Nashori FH, Diana RR. Perbedaan kualitas tidur dan kualitas mimpi antara mahasiswa laki-laki dan mahasiswa perempuan. Jurnal Psikologi. 2005;16:2.

2. Putra SR. Tips sehat dengan pola tidur tepat dan cerdas. Yogyakarta: Penerbit Buku Biru, 2011; p.5-130.

3. Mardjono M, Sidharta P. Neurologi klinis dasar. Jakarta: Dian Rakyat, 2009; p. 187-192

4. The sleep survey Great British; 2012. (cited 2012 oct 22). Available from: http://www.greatbritishsleepsurvey.com/2 012report/

5. Dewi SK. Faktor-faktor risiko yang berkaitan dengan prevalensi kurang tidur kronis pada mahasiswa didaerah istimewa Yogyakarta. Jurnal kesehatan Surya Medika. Yogyakarta: 2009. (diakses tanggal 25 oktober 2012). Dikutip dari: http://www.skripsistikes.wordpress.com

6. Sastroasmoro S. Ismael S. Dasar - dasar metodologi penelitian klonis. (14 $\left.{ }^{\text {th }} \mathrm{Ed}\right)$. Jakarta: Sagung Seto; 2011.

7. Kusumaningsih Y. Faktor yang mempengaruhi prestasi belajar. Jakarta: Fakultas Ekonomi Universitas Indonesia; 2009.

8. Aini N. Hubungan antara pola tidur dengan prestasi belajar pada siswa SMA Dharma Pancasila. Medan: Fakultas Kedokteran Universitas Sumatera Utara; 2011. 